\title{
Towards improving the supervision of postgraduate students in Tanzanian higher learning institutions
}

\author{
Komba, Sotco Claudius $\square$ \\ Sokoine University of Agriculture,Tanzania (sotratz@yahoo.com)
}

Chiwamba, Sarah Vincent

Sokoine University of Agriculture, Tanzania (edmund_sarah@yahoo.com)

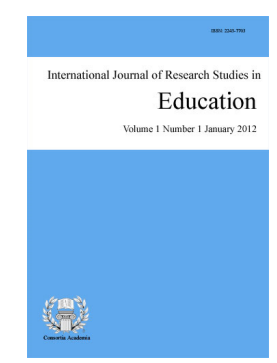

ISSN: 2243-7703 Online ISSN: 2243-7711

Received: 13 June 2016

\begin{abstract}
In recent years, Tanzanian higher learning institutions have attracted many candidates to pursue various postgraduate programmes. However, some higher education stakeholders have echoed their concerns that the number of postgraduate students who successfully graduate from the institutions is low, despite the increase in postgraduate enrollment. Supervisors have consistently been identified by postgraduate students as the main source of either delaying graduation or dropping from the postgraduate studies. This study was conducted in Tanzania, involving 76 academic staff, including 42 males and 34 females, from four public universities and two private universities. The study was designed to achieve two specific objectives: First, to examine the challenges of supervising postgraduate students as experienced by supervisors in Tanzanian higher learning institutions; and secondly, to recommend best practices for improving the supervision of postgraduate students in Tanzanian higher learning institutions. The findings indicated that the supervision of postgraduate students in Tanzanian higher learning institutions faces numerous challenges which could be categorized as student-related and administrative challenges. This calls for collaborative efforts among higher education stakeholders to ensure quality graduates who can contribute significantly to the development of their societies. In view of the findings of this study, it is recommended, among others, that the higher learning institutions should improve administrative and support services to enable both supervisors and supervisees perform their responsibilities effectively.
\end{abstract}

Keywords: supervision; postgraduate students; higher learning institutions 


\section{Towards improving the supervision of postgraduate students in Tanzanian higher learning institutions}

\section{Introduction}

It is generally understood that postgraduate training involves students who are registered for postgraduate diploma, master's degree or doctorate programmes (Komba, 2015). According to Ismail, Abiddin, and Hassan (2011), supervision can be perceived as a two-way interactional process which requires both parties (i.e. student and supervisor) to consciously engage each other within the spirit of professionalism, respect, collegiality and open-mindedness. This implies that the key role players for the successful delivery of postgraduate training are students and supervisors. Piccinin (2000) notes that the relationship between the student and supervisor involves selecting a research topic, planning the research, identifying and acquiring the necessary resources, managing the project, actively conducting the research, carrying out the literature review, analysis and interpretation of the data, writing the thesis, defending it and, publishing the results. Studies have indicated that supervising postgraduate students has been both satisfying and challenging. For example, a study by Schulze and Lessing (2003) revealed, among others, that supervisors experienced some aspects of postgraduate supervision as extremely satisfying. The satisfying aspects of supervision included the feelings by supervisors that they had contributed to the successful completion of the students' research. Another source of satisfaction was found to be the personal relationships supervisors developed with postgraduate students in the course of doing research work. However, Schulze and Lessing (2003) have pointed out numerous challenges such as having inacceptable ground rules, inappropriate plans for the research projects, poor language proficiency and design of empirical investigations. In the same light, Ismail et al. (2011) have categorized the problems experienced by postgraduate students into three: problems in the research design; problems in collecting and processing information; and problems in writing reports.

Many studies have been conducted worldwide to investigate matters related to postgraduate students' supervision and/or challenges faced by students in pursuing their postgraduate studies (Komba, 2015; Ismail et al., 2011; Lee, 2008: Schulze \& Lessing, 2003). However, there are very limited studies conducted in Tanzania, focusing on such a phenomenon. There have been some public concerns from the higher education stakeholders that the number of postgraduate students graduating from the universities is low, despite the increase in postgraduate enrollment (Lugg, Morley, \& Leach, 2007; Bailey, Cloete, \& Pillay, 2010). Supervisors have consistently been identified by students as the main source of either delaying graduation or dropping from the postgraduate studies. Therefore, this study was designed to achieve two specific objectives: First, to examine the challenges of supervising postgraduate students as experienced by supervisors in Tanzanian higher learning institutions; and secondly, to recommend best practices for improving the supervision of postgraduate students in Tanzanian higher learning institutions.

\section{Literature Review}

Postgraduate supervision is a complex process which involves critical conversations and mentorship. It is an interactive process which requires situational awareness, flexibility, and endurance for the parties involved in order to promote social development as well as academic skills. Literature indicates that there are at least two role players in the postgraduate supervision: the student and the supervisor (Lessing \& Schultze, 2003). This implies that the supervision of postgraduate studies is a relationship process between students and supervisors. The relationship is manifested through various stages of postgraduate supervision, ranging from the selection of a research topic to the writing of thesis or dissertation (Ismail et al., 2011). Thus, for students to complete their research projects and dissertations successfully, they need to have supervisors who are interested in their research topics, supportive, and able to get on with. When there is good dialogue between the supervisor and the student, 
Towards improving the supervision of postgraduate students in Tanzanian higher learning institutions

a positive learning experience for the research student is enabled, hence effective supervision.

Different scholars have presented characteristics of effective supervisors in different perspectives. For example, Cullen, Pearson, Saha, and Spear (1994) note that a good supervisor should be approachable, supportive, open minded, prepared to acknowledge errors, organized and thorough, and capable of stimulating and conveying enthusiasm for research. In the same light, Brown and Atkins (1989) point out that an effective postgraduate supervisor is the one who is able to perform, among others, the following roles: determining topic and method, providing access to resources or expertise, arranging field-work, helping to resolve technical problems, suggesting alternatives, suggesting timetable for writing up, giving feedback on progress, and identifying critical path for data collection. Other attributes of a good supervisor, according to Brown and Atkins (1989), are related to the ability to critique the supervisee's draft chapters, authorize student to make decisions and support the same, and extend interest and concern to non academic aspects of student's life. Therefore, based on these attributes, a supervisor is not only supposed to be a teacher and resource base, but also a learning advisor, a co-learner, a counselor and a critical friend.

Studies have indicated that postgraduate students often experience problems which delay their studies or prevent them from graduating on time (Alama, Alamb, \& Rasul, 2013; Helm, 1989; Rademeyer, 1994). The problems can be put into three categories as follows: problems in the research design; problems in the collection and processing of data; and problems in the writing of theses and dissertations (Komba, 2015; Lessing \& Schultze, 2003; Helm, 1989). The causes of such problems are diverse as, for example, Mouton (2001) points inexperience of the students in postgraduate studies as one of the causes. Other causes include poor supervision or inefficient systems within the higher education institutions (Komba, 2016; Rademeyer, 1994). However, other scholars view the problems facing postgraduate supervision in a more elaborate perspective. For example, Alama et al. (2013) identify the following problems facing postgraduate supervision: inadequate supervision which is translated into lack of supervisor's experience, commitment, and/or time; student emotional and psychological problems; lack of understanding and communication between supervisor and student; and student's lack of knowledge, skills, training or experience in research methods. Other problems are related to family and work commitment, lack of financial support, inadequate administrative or institutional support, and poor research infrastructure and environment. When these problems are carefully examined, it seems that the postgraduate supervision does not only face administrative problems, but also psychological, social, and economical problems.

In recognition of the challenges and problems facing the postgraduate supervision process, different scholars have given varied suggestions for improving the process. For example, Ismail, et al., (2011) note that for the supervision to be effective, it is pertinent for supervisors to be knowledgeable and skilled in the research field. Similarly, Frischer and Larsson (2000) and Phillips and Pugh (2000), cited in Ismail et al. (2011), are of the view that the supervision of postgraduate students can be effective if students are enabled to select a supervisor based on the key factor of whether the latter has an established research record and is continuing to contribute to the development of their discipline. In the same attempt to address challenges and problems of postgraduate supervision, Lessing and Schultze (2003) recommend the adoption of a seminar approach which views research as a process, rather than a product. Through this approach, students should be encouraged to talk about their work and progress regularly. The other reasonable proposal for effective supervision is given by Nulty, Kileyb, and Meyersc (2008) who recommend the adoption of different supervisory practices dependent on the students' needs, their progress as postgraduate students, and the nature of the relationships they have had with others involved in the supervisory process. This is particularly important because students' needs are heterogeneous and thus supervisors need to tailor their approaches to guiding individuals, rather than adopting a general model applicable to all students.

It is worth noting that most of the available literature on postgraduate supervision has focused on experiences of either supervisors or students in the supervision of postgraduate students' research outside Tanzania (Mafa \& Mapolisa, 2011; Ismail et al., 2011; Nulty et al., 2008; Graham, 1999; Lessing \& Schultze, 
Komba, S. C., \& Chiwamba, S. V.

2003). Despite the existence of some challenges and problems in the supervision of postgraduate students in Tanzanian higher education institutions, there are hardly any studies which have investigated the phenomenon, especially from the supervisors' point of view. This study was, thus, an attempt to fill in this knowledge gap.

\section{Methodology}

This study was conducted in Tanzania for a period of six months, from August 2015 to February 2016. A survey research design was employed in which 76 academic staff, including 42 males and 34 females, from four public universities and two private universities were involved. The sample composition was as presented in Table 1.

\section{Table 1}

Sample Composition

\begin{tabular}{|c|c|c|c|c|c|c|}
\hline \multirow{2}{*}{$\mathrm{S} / \mathrm{N}$} & \multirow{2}{*}{ Institution } & \multirow{2}{*}{ Status } & \multicolumn{3}{|c|}{ Academic rank of staff } & \multirow{2}{*}{ Total } \\
\hline & & & Lecturer & Senior Lecturer & Professor & \\
\hline 1 & MU & Public & 7 & 1 & - & 8 \\
\hline 2 & SUA & Public & 7 & 8 & 2 & 17 \\
\hline 3 & UDOM & Public & 9 & 9 & - & 18 \\
\hline 4 & UDSM & Public & 7 & 11 & 3 & 21 \\
\hline 5 & TEKU & Private & 6 & - & - & 6 \\
\hline 6 & SAUT & Private & 4 & 2 & - & 6 \\
\hline Total & & & 40 & 31 & 5 & 76 \\
\hline
\end{tabular}

The academic staff, including lecturers, senior lecturers and professors, were selected based on their records of supervising postgraduate students in the past five years. Since the study was qualitative in nature, researchers used mainly interviews to collect the required data. The use of interviews ensured that in-depth data were collected from the participants to address the two objectives of the study as presented in the introduction section of this article. The interview questions were limited to issues related to the two main themes: challenges of supervising postgraduate students and best practices for improving the supervision of postgraduate students in Tanzanian higher learning institutions. During the process, each interview session lasted for about 20 minutes and the sessions took place in the respondents' offices and those who were missing in their offices, were interviewed via telephone calls. The collected data were analyzed using content analysis and presented thematically to reflect the objectives of the study.

\section{Findings and Discussion}

As pointed out earlier, this study sought to achieve two main objectives as follows: to examine the challenges of supervising postgraduate students as experienced by supervisors in Tanzanian higher learning institutions and recommend best practices for improving the supervision of postgraduate students in Tanzanian higher learning institutions. The findings of this study are presented according to the two main themes as follows:

\subsection{Challenges of supervising postgraduate students as experienced by supervisors}

The first objective of this study sought to examine the challenges experienced by supervisors in supervising postgradauate students. After interviewing the academic staff in the selected universities, the responses were as presented in Table 2. 
Towards improving the supervision of postgraduate students in Tanzanian higher learning institutions

Table 2

Challenges of supervising postgraduate students $(N=76)$

\begin{tabular}{clc}
\hline Category & \multicolumn{1}{c}{ Specific challenges } & Percentage \\
\hline Student-related challenges & Too much dependency on the supervisor & $87 \%$ \\
& Lack of committment by some students & $62 \%$ \\
& Poor reading and writing skills & $79 \%$ \\
& Plagiarism & $96 \%$ \\
Administrative challenges & Too many students to supervise & $94 \%$ \\
& Bureaucratic processes for approving proposals & $68 \%$ \\
& Poor remuneration for supervisors & $92 \%$ \\
& Admission of weak students & $58 \%$ \\
& Inadequate facilities & $93 \%$ \\
\hline
\end{tabular}

\subsubsection{Student-related challenges}

Interviews with academic staff in the sampled universities revealed that some of the challenges of supervising postgraduate students emanate from students themselves. These include the following:

Too much dependency on the supervisor - Too much dependency on the supervisors was one of the challenges, which was reported by $87 \%$ of the respondents. On this aspect, the respondents explained that the majority of students think that their supervisors are responsible to assist them accomplish everything as far as their research works are concerned. For example, one of the interviewed respondents had this to report:

...some of my postgraduate students are too dependent on me. In fact, they want me to do everything for them. Whenever I assign them to accomplish something, they repeatedly come back to me and ask for assistance on how to go about doing the assignments. This is despite the efforts I make beforehand to explain to them how they should accomplish the assignments... (Respondent number 23).

There were many other similar observations from other respondents, indicating that too much dependency on the supervisor was one of the serious challenges of supervising postgraduate students. This implied that the postgraduate students were less autonomous and lacked confidence as far as self direction in their learning is concerned. This tendency is likely to contribute towards students' delays to graduate because usually the supervisors have many students to supervise. This means that students who work hard and independently are more likely to make quick progress than their counterparts who depend more on their supervisors. The findings do partly concur with those of Sidhu, Kaur, Choo, and Fook (2015) who found that the majority of postgraduate students were independent of their supervisors in terms of using digital tools but rather dependent on supervisors in academic matters, including writing proposals, collecting and analyzing data and writing the final reports. Thus, while some students are too dependent on their supervisors in everthing, other students may be dependent only in some aspects or during certain stages of their research works.

Lack of commitment - Postgraduate programmes are too involving such that students need to be committed in order to complete their studies on time. In this study, more than two-thirds (62\%) of the respondents reported that some students lacked commitment in their research works. For example, one of the respondents explained that some students were not working on the comments they were being given and they were, instead, pre-occupied by many other activities, including part-time teaching in higher learning institutions. The other respondent had this to state:

...when postgraduate students do not complete their studies on time, the supervisors are always to blame. But, this is not always true. I have some students under my supervision who are not committed with their studies. Last month, I discussed with one of my students about his research work and agreed that we would meet again after a week for another discussion. Since then, I have never seen the student again... (Respondent number 51). 
This quote implies that some students do not abide by instructions given by their supervisors, which makes it difficult for the supervision process to be smooth. Generally, lack of commitment by some students was considered by respondents as one of the factors for slow progression and/or delayed completion of postgraduate students. The observation seems to be surprising because usually postgraduate students register for the postgraduate training with some motivation to pursue the programmes. The motives could be related to qualifications, current career, potential future career, interest, and professional and social networks (Komba, 2015; Ho, Kember, \& Hong, 2012).

Poor reading and writing skills - It is generally accepted that postgraduate students are required to have sound reading skills to enable them gain an accurate and deep intuitive understanding of their topics of research and peripheral issues. In addition, the students need to have writing skills which are useful when developing their research proposals and writing research reports (i.e. theses or dissertations). This means that reading and writing skills are very important in the pursuance of postgraduate studies. In this study, poor reading and writing skills were among the challenges of supervising postgraduate students, reported by $79 \%$ of the respondents, as indicated in Table 2. The respondents explained that the majority of students under their supervision exhibited great weaknesses when they were given reading assignments and when they presented their research findings in writing. For example, one of the respondents had this to report:

...I have nine students under my supervision. Out of these, seven are very weak in writing skills. Sometimes I completely fail to comprehend what they present in their works...no paragraphs....no punctuation marks...you cannot recognize where a sentence starts and where it ends. It is really a big challenge. When you give them reading assignments, their reading is at a very slow pace and quite often, they do not complete the reading assignments... (Respondent number 4).

There were many other similar responses, indicating that poor reading and writing skills were a great challenge in the supervision of postgraduate students.

It is worth noting that reading and writing skills constitute an integral part of postgraduate study, without which, students are likely to face challenges. Findings in applied linguistics have consistently shown a strong correlation between reading proficiency and academic success at all ages from the primary school right to university level (Komba, 2015). It should be noted that one of the stages of wring research proposals and reports is reviewing literature. The review of literature involves reading a lot of texts relevant to one's topic of research. If students are not skilled to find relevant literature and use reading strategies to obtain what is required in an efficient manner, the progression from one stage to the next is likely to be negatively affected. With regard to writing skills, it is evident that postgraduate students do a lot of writing, from when they develop their research proposal to the time they write final research reports (Pretorious, 2007). Therefore, the findings that students were weak in both reading and writing skills seemed to be a great challenge as far as the supervision of postgraduate students is concerned.

Plagiarism - According to Park (2003), plagiarism involves literary theft, stealing (by copying) the words or ideas of someone else and passing them off as one's own without crediting the source. In this study, plagiarism was reported by $96 \%$ of the respondents as a challenge in the supervision of postgraduate students. The respondents explained that the majority of students practiced either direct plagiarism or accidental plagiarism in writing their research proposal and final reports. In direct plagiarism, it was reported that some students wrote word-for-word transcription of sections of other people's works, without acknowledging or using quotation marks. On the other hand, accidental plagiarism involved negligence to cite sources of information, or misquoting sources, or unintentionally paraphrasing a source by using similar words, groups of words, and/or sentence structure without acknowledgement. Regarding this aspect, one of the respondents had this to state:

...when one of my students was developing a proposal, it was interesting to note that the candidate was writing the proposal at a very high speed. Whenever I gave the candidate 
Towards improving the supervision of postgraduate students in Tanzanian higher learning institutions

deadlines for submitting sections of the proposal, she would come with completed sections, a couple of days before the set deadline. One day, I told her to send me soft copy of her proposal and scanned for duplicated content, using a plagiarism checker. I realized that more than $90 \%$ of the content had been copied from other people's works!.. (Respondent number 62).

This explanation shows that plagiarism is one of the greatest challenges of supervising postgraduate students in Tanzanian higher learning institutions. Nevertheless, literature indicates that plagiarism is a worldwide phenomenon among students and studies have indicated different reasons for this practice. For example, Riasati and Rahimi (2013) found a number of reasons for plagiarism, including students' shallow understanding of the concept of plagiarism, poor linguistic abilities, poor research and writing skills, and lack of familiarity with and interest in the topic assigned to them. In the same light, Park (2003) points out several contingent motives of plagiarism by students. These include genuine lack of understanding, temptation and opportunity, desire for better grades, poor time management, lack of commitment, and negative attitudinal feelings towards assignments and tasks that teachers think have meaning but they do not. Considering the negative effects of plagiarism, it high time higher learning institutions in Tanzania developed cohesive mechanisms for dealing with such a form of dishonest behavior.

\subsubsection{Administrative challenges}

Apart from student-related challenges, other challenges of supervising postgraduate students, as reported by the respondents, could be categorized as administrative challenges. These include the following:

Too many students to supervise - When postgraduate students are admitted to the universities, the responsible offices within the universities have the role of asssigning supervisors for each student. In the course of accomplishing this important arrangement, $94 \%$ of the respondents reported that they were assigned to supervise many students such that they were unable to read critically works of all students under their supervision. As a result, the works of some students become sub-standard and the pace of progression of students from one stage to the next is hampered. For example, one of the respondents stated that he had 21 students under his supervision and he was expecting to be assigned some more students, considering that he was the only expert in his area of specialization, within his Department. Many other respondents reported that they had 10-15 students to supervise, which made it difficult for them to guide the students effectievely. In addition to having many students to supervise, it is worth noting that the supervisors have other roles to play, including teaching, conducting research and undertaking outreach activities.

These findings seem to concur with those of Kimani (2014) who noted about the number of staff in higher learning institutions being not proportional to the number of students admitted for postgraduate training. The author writes that because of increased demand for higher education, some departments do not have adequate staff who have required qualifications to supervise the students. This affects negatively the quality of students research works as the available supervisors are overworked, considering the big number of students they have to supervise.

Bureaucratic processes for approving proposals - Bureaucratic processes for approving proposals was one of the challenges of supervising postgraduate students which was reported by $68 \%$ of the respondents. On this aspect, it seemed that, in some universities, a postgraduate student was required to make proposal presentations at three different levels (i.e. at the level of department, college/faculty/directorate, and university) before the proposal is approved. Although the aim of having such stages for approving proposals was meant to subject the proposals to careful scrutiny by different people before approval, the respondents felt that such bureaucracy was unnecesary. Giving reasons for discouraging such bureaucratic processes, one of the respondents had this to say:

...such bureaucratic processes are not necessary. We can avoid them if we like. For example, if we believe that departments in which our postgraduate students register for various programmes have experts in relevent fields, is it necessary for candidates to present their proposals again at 
university level after having presented the same at departmental level? This is waste of time and efforts. Sometimes the panel members of the university committee which approves the proposals are not necessarily experts in the candidate's proposed research topic... (Respondent number 9).

This respondent implies that departments in which the candidates are registered for their programmes should be entrusted with the task of approving students' proposals so that students do not unnecessarily delay to complete their studies.

In the same vein, the respondents stated that it was taking so long for the relevant offices to schedule meetings at diffrent levels for the students to make their proposal presentations. For example, one of the respondents stated that her candidate had to wait for three months before his proposal was scheduled for presentation at university level. This was after the candidate had presented the proposal at both departmental and faculty levels.

Poor remuneration for supervisors - Another challenge of supervising postgraduate students which was reported by $92 \%$ of the respondents was poor remuneration for the supervisors. The majority of the supervisors stated that, although the supervision role was by itself academically satisfying, they deserved to be fairly compensated for their time and efforts. However, the respondents expressed their feelings that they were poorly remunerated such that they lacked motivation for doing the job effectively. During interviews with the respondents, one of them had this to report:

...supervision of postgraduate students is a challenging task. There are moments when I have to work under very high pressure...reading my students' works and doing other activities, including teaching. Surely, I deserve an attractive remuneration, considering that the students pay fees for their programmes...what I am currently being paid as supervision allowance is just peanut!.. (Respondent number 47).

There were many other similar responses, indicating that the remuneration package for supervising postgraduate students in Tanzanian higher learning institutions was unattractive.

This observation is suggestive of the fact that higher learning institutions need to review their guidelines for supervising postgraduate students, especially on the aspect of remuneration package attached to supervision task. The current practice is that Tanzanian higher learning institutions offer different remuneration packages, for supervising postgraduate students. In addaition to financial gains, the other way of motivating the supervisors would be awarding points for supervision roles which would be used when one is considered for promotion.

Admission of weak students - Some respondents (58\%) stated that the admission of weak students to pursue various programmes in the universities was among the challenges of supervising postgraduate students. This was revealed during interviews with some respondents who reported that, following an increase in the number of universities in the country, some universities have decided to lower cutt-off points for entry into various postgraduate programmes, because of competition for the pool of potential postgraduate students. The respondents explained that this move has affected negatively the quality of candidates who join the universities to pursue postgraduate programmes. For example, one of the respondents had this to state:

...currently, the number of higher learning institutions in Tanzania, offering undergraduate programmes, has increased. Although the number of students graduating from these institutions has risen, not all of them qualify and/or continue with postgraduate studies. Therefore, universities offering postgraduate programmes, have to compete for a small pool of potential postgraduate students. If I compare my current students with those I had in the past, most of my current students are academically weak and I can tell you that most of these joined the university using very low entry qualifications... (Respondent number 35).

This response and many other responses indicated that some of the admitted postgraduate students are 
Towards improving the supervision of postgraduate students in Tanzanian higher learning institutions

academicllay weak, which makes it challenging for the supervisors to work smoothly with such students.

It is worth noting that all higher learning institutions offering postgraduate programmes in Tanzania have guidelines for the admission of postgraduate students and the criteria are explicitly stated. Based on these findings, two arguments could be given. First, it may seem that some higher learning institutions do not either abide by the guidelines set for the admission of postgraduate students or have purposely lowered the entry qualifications to attract many students, including weak students. Secondly, it could also be that some students submit undergraduate degree qualifications which indicate that they qualify for postgraduate studies while their actual capabilities are weak. This could be the result of poor assessment procedures at undegraduate level. Therefore, the higher learning institutions need to devise mechanisms which can ensure that students who are registered for postgraduate studies are only those with potential abilities to undertake studies at such level. One of the ways could be introducing oral examinations, in adition to certificates submitted to the host higher learning institutions.

Inadequate resources - Another challenge which was reported by $93 \%$ of the respondents was inadequate resources for the training of postgraduate students, including supervision. The respondents explained that, in recent years, the number of students who are joining universities for both undergraduate and postgraduate programmes has increased tremendously. However, the respondents stated that the increase in the number of students is not proportional to the available human and material resources. For example, one of the respondents had this to report:

... despite the increase in the number of students in this university, laboratory equipment, library facilities, and the number of academic staff have almost remained the same in the past five years. This has negatively affected the quality of training for postgraduate students... (Respondent number 14).

Another respondent had this to state:

...postgraduate studies involve the reading of many published works which are found online, including journal articles and e-books. The online materials can only be accessed if there is reliable internet connection. My students are always complaining that internet connection is not reliable, around here!... (Respondent number 5).

If the voices of these two respondents are critically analysed, it could be deduced that resources, such as academic staff, laboratory equipment, library facilities, and internet sevices, were inadequate in the higher education institutions.

If these findings are carefully scrutinized, it is evident that the supervision of postgraduate students is faced with numerous challenges which need to be addressed for effective supervisory practices. The other thing which is worth noting is that such challenges are not only typical of the Tanzanian higher learning institutions, but a worlwide phenomenon. This calls for collaborative efforts among higher education stakeholders in order to redress the situation and produce quality graduates who can contribute significantly in the development of their societies.

\subsection{Recommendations for improving the supervision of postgraduate students}

The second objective of this study sought to elicit responses from the respondents on the best practices for improving the supervision of postgraduate students in Tanzanian higher learning institutions. The responses were as presented in Table 3 . 


\section{Table 3}

Recommendations for improving the supervision of postgraduate students $(N=76)$

\begin{tabular}{lc}
\hline \multicolumn{1}{c}{ Recommendation } & Percentage \\
\hline All postgraduate students should be taught academic writing skills & $96 \%$ \\
Strict admission criteria for postgraduate students should be adopted & $91 \%$ \\
More staff should be employed to manage the increasing number of students & $94 \%$ \\
Rates for supervision allowance should be reviewed & $94 \%$ \\
Material resources for training postgraduate students should be improved & $89 \%$ \\
Research proposals should be discussed and approved at departmental level & $92 \%$ \\
\hline
\end{tabular}

As shown in Table 3, the respondents provided many recommendations which they felt that they could aid in improving the supervision of postgraduate students.

First, 96\% of the respondents recommended that all postgraduate students should take an intensive tailor-made academic writing skills courses in order to enable them gain skills which are useful in writing their research proposals and reports in their areas of specialization. The respondents explained that since the majority of their supervisees exhibitted great weaknessess in writing, the introduction of writing skills courses for all postgraduate students would be a remedy to this challenge. Stressing on this aspect, one of the respondents had this to report:

\section{...all undergraduate students take compulsory communication skills courses which enable them acquire basic skills of communication, including writing. It is high time the universities introduced compulsory writing skills courses which will aid in addressing the writing problems exhibited by our postgraduate students... (Respondent number 3 ).}

In addition, 94\% of the respondents recommended that the higher learning institutions should recruit more academic staff in order to make their numbers proportional to the increasing number of students, joining the institutions. The respondents explained that one of the solutions for reducing the number of supervisees per supervisor was to recruit more academic staff, especially for the fields attracting many postgraduate students.

The other recommendation given by the respondents was on the rates used in paying supervision allowance to the supervisors. On this aspect, $94 \%$ of the respondents stated that the existing rates, in most of the institutions, should be reviewed since they were outdated. The respondents explained further that, considering the magnitude of the job they were doing, it was important to revise the rates in order to motivate them.

Other respondents (92\%) recommended that students' research proposals should be presented, discussed and approved at departmental level where experts in the candidate's field of specialization are found. The respondents explained that higher organs within the respective institutions should only be made to note on what transpires in relevant academic units, where postgraduate students are registered. According to the respondents, this would not only enable students to progress in their studies without unnecessary delays, but also eliminate as much bureaucracy as possible.

Also, it was recommended by $91 \%$ of the respondents that higher learning institutions should adopt and abide by strict admission criteria to get rid of admitting weak students, who usually become a burden to supervisors. The respondents explained that although the criteria for admitting students were clearly stipulated, some of them were no longer useful. They, further, explained that some of the graduates who constitute the pool of potential applicants for postgraduate students do not exhibit pre-requisites - in terms of knowledge and skills for postgraduate studies, although their certificates qualify them for the same. In view of this, the respondents recommended that, in addition to having minimum entry qualifications, oral examinations should be introduced to discriminate those who are able from those who are unable to follow postgraduate studies.

The other recommendation was that the universities and other higher learning institutions should strive to increase material resources needed for the training of postgraduate students. This was recommended by $89 \%$ of 
Towards improving the supervision of postgraduate students in Tanzanian higher learning institutions

the respondents. The respondents explained that what made the higher education institutions to exist is the presence of students who join the institutions with certain expectations. According to the respondents, students' expectations can only be realized if the institutions create conducive learning environment, including the provision of quality and adequate material resources. Therefore, the respondents were of the view that the institutions should prioritize the purchase of material resources during institutional budget preparation because training is one of their core functions.

\section{Conclusions and Recommendations}

This study has revealed that the supervision of postgraduate students in Tanzanian higher learning institutions faces numerous challenges which could be categorized as student-related and administrative challenges. However, the challenges are not only typical of the Tanzanian higher learning institutions, but a worldwide phenomenon. This calls for collaborative efforts among higher education stakeholders in order to produce quality graduates who can contribute significantly to the development of their societies.

Based on these findings, the following recommendations are made: First, the supervisors should be motivated to perform their job well. One of the ways of doing this would be awarding them points for supervisory roles, in addition to financial gains, which have to be counted during promotions. Secondly, the roles and responsibilities of the supervisor and supervisee should be made clear to all participants in the supervision. This should be done at the beginning of the supervision process to avoid unnecessary misunderstandings. Lastly, the higher learning institutions should improve the administrative and support services to enable both supervisors and supervisee perform their responsibilities effectively.

\section{References}

Alama, F., Alamb, Q., \& Rasul, M. G. (2013). A pilot study on postgraduate supervision. Procedia Engineering, 56, 875 - 881. http://dx.doi.org/10.1016/j.proeng.2013.03.210

Bailey, T., Cloete, N., \& Pillay, P. (2010). Universities and economic development in Africa: The case study of Tanzania and University of Dar es Salaam. Retrieved at http://chet.org.za/files/uploads/reports/Case\%20Study\%20\%20Tanzania\%20and\%20University\%20of\% 20Dar\%20es\%20Salaam.pdf

Binns, T., \& Potter, R. (1989). Improving the effectiveness of postgraduate supervision: Never mind the quality, feel the width. Journal of Geography in Higher Education, 13(2), 210-216. http://dx.doi.org/10.1080/03098268908709089

Brown, G., \& Atkins, M. (1986). Academic staff training in British universities: Results of a national survey. Studies in Higher Education, 11(1), 29-42. http://dx.doi.org/10.1080/03075078612331378441

Cullen, D., Pearson, M., Saha, L. J., \& Spear, R. H. (1994). Establishing effective PhD supervision. Canberra: AGPS.

Ezebilo, E. E. (2012). Challenges in postgraduate studies: Assessments by doctoral students in a Swedish University. Higher Education Studies, 2(4), 49-57. http://dx.doi.org/10.5539/hes.v2n4p49

Ho, A., Kember, D., \& Hong, C. (2012). What motivates an ever increasing number of students to enroll in part-time taught postgraduate awards? Studies in Continuing Education, 34(3), 319-338. http://dx.doi.org/10.1080/0158037X.2011.646979

Ismail, A., Abiddin N., Z., \& Hassan, A. (2011). Improving the development of postgraduates' research and supervision. International Education Studies, 4, 1. Retrieved from http://www.ccsenet.org/journal/index.php/ies/article/view/9100 http://dx.doi.org/10.5539/ies.v4n1p78

Kimani, E. N. (2014). Challenges in quality control for postgraduate supervision. International Journal of Humanities Social Sciences and Education, 1(9), 63-70.

Komba, S. C. (2016). Challenges of writing theses and dissertations among postgraduate students in Tanzanian higher learning institutions. International Journal of Research Studies in Education, 5(3), 71-80. http://dx.doi.org/10.5861/ijrse.2015.1280 
Komba, S. C., \& Chiwamba, S. V.

Lee, A. (2008). How are doctoral students supervised? Concepts of doctoral research supervision. Studies in Higher Education, 33(3), 267-281. http://dx.doi.org/10.1080/03075070802049202

Lessing, A. C. and Schulze, S. (2002). Graduate supervision and academic support: students' perceptions. South African Journal of Higher Education, 16(2), 139-149. http://dx.doi.org/10.4314/sajhe.v16i2.25253

Lugg, R., Morley, L., \& Leach, F. (2007). A profile of participation in higher education in Ghana and Tanzania. Working Paper. ESRC-DFID project on Widening Participation in Higher Education in Ghana and Tanzania. Retrieved from http://www.sussex.ac.uk/education/wideningparticipation

Mafa, O., \& Mapolisa, T. (2011). Supervisors' experiences in supervising postgraduate education students' dissertations and theses at the Zimbabwe Open University. International Journal of Asian Social Science, 2(10), 1685-1697.

Morley, L., \& Leach, F., \& Lugg, R. (2007). Widening participation in higher education in Ghana and Tanzania: Developing an equity scorecard. An ESRC/DfID Poverty Reduction Programme funded research project.

Mouton, J. (2001) How to succeed in your master's and doctoral studies. Pretoria, South Africa: Van Schaik.

Nulty, D., Kiley, M., \& Meyers, N. (2009). Promoting and recognizing excellence in the supervision of research students: An evidence based framework. Assessment and Evaluation in Higher Education, 34(6), 693-707. http://dx.doi.org/10.1080/02602930802474193

Park, C. (2003). In other (people's) words: Plagiarism by university students-literature and lessons. Assessment and Evaluation in Higher Education, 28(5), 471-488. http://dx.doi.org/10.1080/02602930301677

Piccinin, S. J. (2000). Graduate student supervision: resources for supervisors and students. Triannual newsletter, Centre for development of teaching and learning (CDTL). CDTLink: University of Ottawa, Canada.

Pretorious, E. (2007). The importance of reading. Frankfurt International School.

Rademeyer, G. (1994). Thesis supervision: getting the genie out of the lamp. South African Journal of Higher Education, 8(2), 92-95.

Riasati, M. J., \& Rahimi, F. (2013). Why do Iranian postgraduate students plagiarize? A qualitative investigation. Middle-East Journal of Scientific Research, 14(3), 309-317.

Sidhu, G. K., Kaur, S., Choo, L. P., \& Fook, C. Y. (2015). Postgraduate students' level of dependence on supervisors in coping with academic matters and using digital tools. A paper presented at 12th International Conference on Cognition and Exploratory Learning in Digital Age (CELDA). Retrieved from https://www.google.com/search?q=sidhu+et+al+pdf\&ie=utf-8\&oe=utf-8\&client=firefox-b-ab\#q=sidhu+ $\underline{\text { et }+\mathrm{al}++2015+\mathrm{pdf}}$ 